\title{
Indirect consequences of COVID-19 on children's health
}

This article was published on $9 \mathrm{Apr}$ 2021 at www.hkmj.org.
Hong Kong Med J 2021:27:160

https://doi.org/10.12809/hkmj208694

To the Editor-Unlike adults, children appear to be fortunately spared from the direct effects of coronavirus disease 2019 (COVID-19). ${ }^{1}$ However, the closure of schools and restrictions on public gatherings, coupled with prolonged social distancing and isolation measures may result in adverse physical and psychosocial consequences for children and adolescents. These consequences include excess mortality due to disruptions to routine healthcare services ${ }^{2}$; developmental delays ${ }^{3}$ and anxiety ${ }^{4}$ associated with school closures; increased susceptibility to cyber bullying due to more frequent social media use, resulting in low selfesteem, depression and anxiety ${ }^{5}$; increased risk of obesity associated with sedentary lifestyle; and poor sleep patterns due to disrupted daily routines. ${ }^{6}$ The authors have witnessed children who are at home because of school closures experiencing dramatic weight gain due to reduced physical activity but increased consumption of junk food (the so-called COVID pandemic obesity syndrome or CObesity syndrome). Children with special physical or psychosocial needs, pre-existing mental health problems, or migrant backgrounds are particularly vulnerable to this adversity.

The United Nations provides guidance to nations and non-government organisations on safeguarding and mitigating the impacts of COVID-19 on children globally, including the most vulnerable children living in low-income countries, ${ }^{8}$ with progress advised on three fronts: information, solidarity, and action. ${ }^{9}$ In order to mitigate this public health threat, regular and emergency child and adolescent psychiatric services must be maintained. Moreover, further research must be carried out to understand the psychosocial effects of social distancing and home schooling, identify risk and resilience factors, prevent long-term mental health consequences especially child maltreatment, and explore the feasibility and optimal model of telepsychiatry. We hope that these issues can be considered in planning exit strategies as countries around the world transform from the "BC" (Before COVID) era to a 'new normal' of the "AC" (After COVID) era.

\section{Author contributions}

All authors contributed to the drafting of the letter and critical revision for important intellectual content. All authors approved the final version for publication and take responsibility for its accuracy and integrity.

\section{Conflicts of interest}

As an editor of the journal, KL Hon was excluded from the review process for this letter. The other authors have no conflicts of interest to disclose.

Karen KY Leung ${ }^{1}$, MB, BS, MRCPCH

Samantha PW Chu²

$\mathrm{KL} \mathrm{Hon}{ }^{1,3} *$ MB, BS, MD

TF Leung ${ }^{3}$, MB, ChB, MD

${ }^{1}$ Department of Paediatrics and Adolescent Medicine, Hong Kong

Children's Hospital, Hong Kong

2 Faculty of Medicine, The Chinese University of Hong Kong, Hong Kong

${ }^{3}$ Department of Paediatrics, The Chinese University of Hong Kong, Hong Kong

*Corresponding author: ehon@hotmail.com

\section{References}

1. Shekerdemian LS, Mahmood NR, Wolfe KK, et al. Characteristics and outcomes of children with coronavirus disease 2019 (COVID-19) infection admitted to US and Canadian pediatric intensive care units. JAMA Pediatr 2020 May 11. Epub ahead of print.

2. Banerjee A, Pasea L, Harris S, et al. Estimating excess 1-year mortality associated with the COVID-19 pandemic according to underlying conditions and age: a populationbased cohort study. Lancet 2020;395:1715-25.

3. Soto-Icaza P, Aboitiz F, Billeke P. Development of social skills in children: neural and behavioral evidence for the elaboration of cognitive models. Front Neurosci 2015;9:333.

4. Ng KC. Coronavirus: stress over university entrance exams has skyrocketed amid Hong Kong school closures, study finds. South China Morning Post [newspaper on the internet]. 2020 Apr 5. Available from: https://www. scmp.com/news/hong-kong/education/article/3078513/ coronavirus-stress-over-university-entrance-exams-has. Accessed 17 May 2020.

5. Reichert F, Lam P, Loh EK, Law N. Hong Kong students' digital citizenship development. Initial findings. April 2020. The University of Hong Kong. Available from: https://www.ecitizen.hk/publications/reports. Accessed 19 May 2020.

6. El Shakankiry HM. Sleep physiology and sleep disorders in childhood. Nat Sci Sleep 2011;3:101-4.

7. Golberstein E, Wen H, Miller BF. Coronavirus disease 2019 (COVID-19) and mental health for children and adolescents. JAMA Pediatr 2020;174:819-20.

8. United Nations Sustainable Development Group. Policy brief: The impact of COVID-19 on children. April 2020. Available from: https://unsdg.un.org/resources/policybrief-impact-covid-19-children. Accessed 11 Jun 2020.

9. UNICEF. COVID-19 \& children rapid research response. 2020. Available from: https://www.unicef-irc.org/covid19. Accessed 11 Jun 2020. 